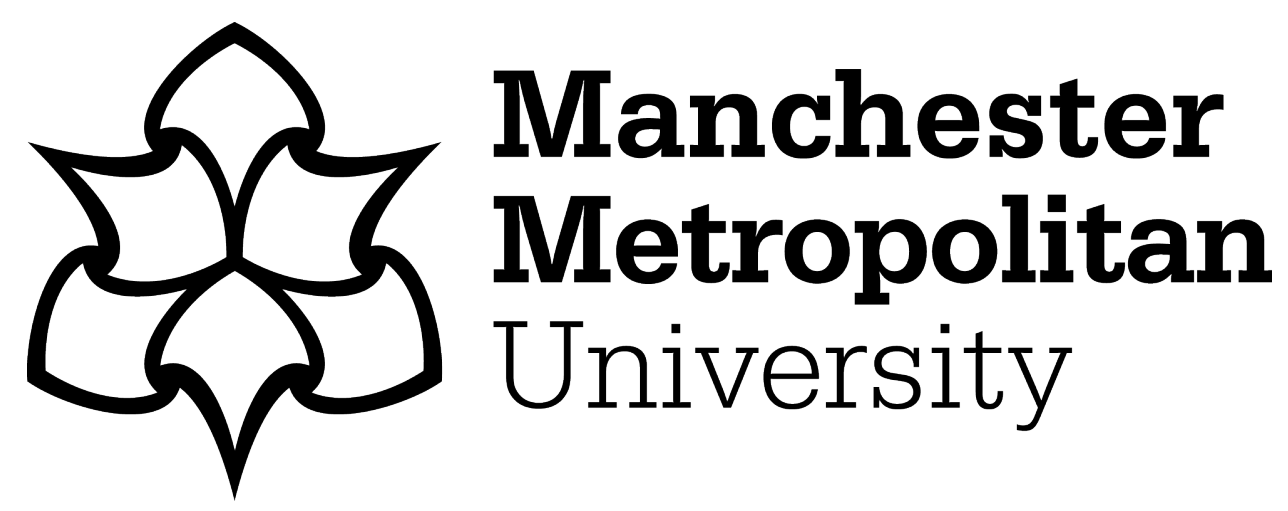

Buil-Gil, D, Moretti, A ORCID logoORCID: https://orcid.org/0000-0001-65439418, Shlomo, N and Medina, J (2021) Worry about crime in Europe: a model-based small area estimation from the European Social Survey. European Journal of Criminology, 18 (2). pp. 274-298. ISSN 1477-3708

Downloaded from: https://e-space.mmu.ac.uk/625179/

Version: Accepted Version

Publisher: SAGE Publications

DOI: https://doi.org/10.1177/1477370819845752

Please cite the published version 


\title{
Worry about crime in Europe. A model-based small area estimation from the European Social Survey
}

\begin{abstract}
Worry about crime is known to be higher in some European regions than others. However, cross-national surveys, which are the main source of information to map worry about crime across Europe, are designed to be representative of large areas (countries), and regions often suffer from small and unrepresentative sample sizes. This research produces reliable model-based small area estimates of worry about crime at regional level from European Social Survey data, in order to map the phenomenon and examine its macrolevel predictors. Model-based small area estimation techniques borrow strength across areas to produce reliable estimates of parameters of interest. Estimates of worry about crime are higher in most Southern and Eastern European regions, in contrast to Northern and Central Europe.
\end{abstract}

\section{Keywords}

Fear of crime, model-based estimation, spatial distribution, Fay-Herriot, EBLUP

\section{Full reference}

Buil-Gil, D., Moretti, A., Shlomo, N., and Medina, J. (2019). Worry about crime in Europe: A model-based small area estimation from the European Social Survey. European Journal of Criminology. https://doi.org/10.1177/1477370819845752 


\section{Introduction}

Worry about crime is not homogeneously distributed across space. There are countries where people are more worried about crime and more likely to feel unsafe than others (Hummelsheim et al., 2011; Vauclair and Bratanova, 2017; Visser et al., 2013). In Europe, cross-national surveys show that Southern and Eastern-European countries have the highest levels of worry about crime, while worry is lower in Scandinavia and Central Europe (Jackson and Kuha, 2014). Worry about crime is also known to be unequally distributed across the regions in each country (Fitzgerald et al., 2012; Rueda and Stegmueller, 2015), and it is higher in certain neighbourhoods than others (Brunton-Smith and Sturgis, 2011).

Different and heterogeneous measures have been used to capture the citizens' emotions about the threat of becoming victims of crime (Gabriel and Greve, 2003; Rader, 2004). Questions about perceived risk, feelings of unsafety, fear, concern and worry about crime have been equally used to theorise an ambiguous construct of 'fear of crime' (DuBow et al., 1979), and hence there is a need to provide conceptual clarity and precision in the field. Jackson and Gouseti (2014) argue that the concept of 'worry about crime' captures most people's anxiety-producing concerns about crime, and it draws links between perceived threats and emotions, thus being preferred to examine the citizens' emotions about crime (Williams et al., 2000). Conversely, the fear of crime is an emotional response that humans have in very specific threatening situations, and it is 
difficult to operationalise and measure (Castro-Toledo et al., 2017; Solymosi et al., 2015). According to Hough (2004), fear of crime can be referred to as a 'mental event' taking place at a specific time and place, while worry is a 'mental state' reflecting concerns about crime and insecurities. Some authors also distinguish between 'functional' and 'dysfunctional' worry, where the prior refers to the type of worry that improves wellbeing by making citizens take precautions and the latter refers to the type of worry that damages citizens' quality of life (Gray et al., 2011).

Research has tended to agree that emotions about the threat of victimisation have different meanings and explanatory processes at different geographic scales. At the individual level, these emotions tend to be explained as the result of the citizens' experience with crime; at a neighbourhood level, these are understood as a function of people's understanding of their local areas; and at a macro level, it can be interpreted as "a social phenomenon shaped by media and as part of a generalised and diffused anxiety generated by current global and social changes" (Ceccato, 2012: 10).

Cross-national differences in levels of worry about crime and feelings of unsafety are partly explained by countries' levels of social and economic insecurity (Vauclair and Bratanova, 2017; Vieno et al., 2013). These processes are also reflected in an unequal regional distribution of worry about crime within countries (Fitzgerald et al., 2012; Rueda and Stegmueller, 2015), and thus the regions' characteristics are also likely to affect the citizens' emotions about crime. This is why some argue that, at a macro level, emotions 
about crime shall be interpreted as 'umbrella sentiments' that hide not only crime-related concerns but also social and economic anxieties (Vieno et al., 2013).

The conceptual framework of 'worry about crime' is thus preferred to examine emotions about the threat of victimisation at a macro-geographic level. The interpretation of such emotions and their macro-level distribution resemble 'mental states' of general concerns and anxieties affected by macro-level socio-economic insecurity, rather than 'mental events' driven by immediate threatening situations. Others prefer the use of measures of feelings of unsafety to conduct macro-level comparisons between countries (e.g. Hummelsheim et al., 2011), but these measures have been highly criticised for struggling to capture the emotional component -either physical responses (fear) or softer ruminations or anxieties (worry)- rather than only perceived risks.

Cross-national analyses of worry about crime are needed to facilitate understanding of its macro-level predictors. And the development of maps of its distribution at regional level are of great value for regional, national and supranational administrators to design and implement targeted policies to reduce concerns and anxieties about the threat of crime. In order to map the worry about crime across countries, crossnational surveys are the most important source of information. These are often designed to record representative samples at a state level, and smaller geographical units (e.g. regions) are unplanned areas and suffer from small and unrepresentative samples. Thus, direct estimates, which use only area-specific sample data, may suffer from low precision. 
Instead, model-based small area estimation techniques make use of auxiliary data to 'borrow strength' across related areas and produce precise estimates in unplanned areas (Rao and Molina, 2015), yet they are underutilised in criminology ${ }^{1}$. This research aims to produce reliable small area estimates of dysfunctional worry about crime at a regional level in Europe based on European Social Survey (ESS) data. By providing these estimates, this article presents the first map of the regional distribution of dysfunctional worry about crime in Europe, identifying subnational internal heterogeneity in levels of worry and providing precise information about its macro-level predictors.

We make use of the Spatial Empirical Best Linear Unbiased Predictor (SEBLUP) under the Fay-Herriot model (Fay and Herriot, 1979), which borrows strength both from related and neighbouring areas (Petrucci and Salvati, 2006). Much like the geographical distribution of crime, emotions about crime are known to be spatially aggregated (Vauclair and Bratanova, 2017; Vieno et al., 2013) and show high levels of spatial autocorrelation (Wyant, 2008). We thus expect to improve the precision of our estimates by borrowing strength from neighbouring areas.

Section 2 discusses the nature, measurement and prediction of worry about crime. Section 3 describes data and methods. Section 4 presents model results, estimates, estimates' reliability checks, and model diagnostics. Finally, section 5 discusses findings and conclusions. 


\section{Background}

\subsection{Concept and measurement of worry about crime}

Criminological research about the emotions about crime cannot be understood without a brief reference to the theoretical quagmire built around the construct of 'fear of crime'. Questions involving potential danger/risk to self or others, fear, concern, worry and anxiety have been equally considered to be about 'fear'. Even when the majority of the community accepts now the definition of 'fear of crime' as an emotional response of dread or anxiety to crime (Ferraro, 1995: 4); numerous questions have been used for its measurement, and most have been criticised for failing to record its multiple dimensions.

Fear of crime have been conceptualised as a multidimensional phenomenon composed of: (a) cognitive perception of being threatened, (b) feeling or emotion of fear, and (c) action tendency or behavioural response (Caro Cabrera and Navarro Ardoy, 2017; Gabriel and Greve, 2003). Gabriel and Greve (2003) argue that a paradigmatic example of the so-called 'fear of crime' should encompass these three dimensions. Thus, questions about feelings of unsafety have been criticised as measures of fear of crime, as they capture perceived risks but not the emotion of threat: respondents might answer 'very unsafe' when they do not experience an emotional response. Conversely, Rader (2004) argues that 'fear of crime' should only refer to the emotional component, while the cognitive perception should be referred to as 'perceived risk' and the behavioural response as 'constrained behaviours', and all three would be dimensions of a larger 
construct named 'threat of victimisation'. There is also a conceptual distinction between dispositional (personal tendency to react fearfully) and situational fear (each episode/event of fear), between concrete and abstract fear, and between its locus of projection (internal or external) (see Caro Cabrera and Navarro Ardoy, 2017; Gabriel and Greve, 2003).

The debate about the concept and measure of fear of crime is still open nowadays. Some argue that even the best measures suffer from lack of precision and suggest a move towards the study of worry about crime (Jackson and Gouseti, 2014; Jackson and Kuha, 2014; Williams et al., 2000). Hough (2004) argues that research on fear of crime should not be equally preoccupied about anxieties, concerns, worries and perceived risks, and concludes that fearfulness if qualitatively different from anxiety and worry: while fear is a 'mental event', worry is a 'mental state'. Fear is an emotional and physiological response that humans have in time- and context-dependent threatening situations (CastroToledo et al., 2017; Solymosi et al., 2015), and thus it is difficult to operationalise and measure. Conversely, worry captures both evaluations of immediate situations and anxiety-producing thoughts about future events (Jackson and Gouseti, 2014).

Jackson and Gouseti (2014) argue two main reasons for focusing on the worry about crime. First, while fear arises only in the presence of immediate dangers, citizens' emotions about crime are usually closer to general concerns and anxieties about the risk of victimisation (worry about crime). Second, the psychological literature about the 
phases of worrying (see Berenbaum's (2010) initiation-termination two phase model) adjusts well the citizens' most common emotions towards crime. Worry starts after one episode of perceived risk of victimisation, but repetitive thought continues until the individual accepts the prospect of an uncertain future threat: "people continue to worry unless they can accept the uncertain future possibility of a threat, and have taken whatever efforts they can to prevent or cope with it" (Jackson and Gouseti, 2014: 1594). Berenbaum (2010: 963) defines worry as (1) repetitive thoughts concerning an uncertain future outcome; (2) the uncertain outcome about which the person is thinking is undesirable; and (3) the experience of having such thoughts is unpleasant. In the case of worry about crime, such thoughts are related to the threat of victimisation. Moreover, citizens' emotions about crime are known to be highly connected to macro-level social and economic insecurities, which can be conceptualised as general concerns or anxieties (worry about crime) but not situational responses of fear (Ceccato, 2012).

In relation to the measurement of worry about crime, the ESS included, in its editions 3, 4 and 5, two questions designed to measure worry about burglary at home and worry about violent crime:

- $\quad$ How often, if at all, do you worry about your home being burgled?

- $\quad$ How often, if at all, do you worry about becoming a victim of violent crime? 
Response options are 'All or most of the time', 'Some of the time', 'Just occasionally' and 'Never'. When the response is other than 'Never', respondents are asked whether this worry has ' '... serious effects on the quality of life', '... some effect' or '... no real effect on the quality of life'. Jackson and Kuha (2014) argue that prior questions were designed, in part, to allow examining cases in which worry damages (or not) respondents' well-being. These questions allow distinguishing between 'functional' and 'dysfunctional' worry. 'Functional' worry can improve well-being by stimulating constructive precautions to make citizens feel safer, in contrast to 'dysfunctional' worry that reduces quality of life (Jackson and Gray, 2010). One could also argue that the combination of these questions might result in a measure that captures the three dimensions that make up the emotions about crime (perceived risk, emotion, and behavioural response).

\subsection{Mapping worry about crime: theory}

The criminological and interdisciplinary studies looking at the geographical distribution of emotions about crimes have grown during the past two decades. On the one hand, environmental micro-level approaches argue that fear of crime episodes are more frequent under certain situational and social organisation circumstances (Castro-Toledo et al., 2017; Solymosi et al., 2015), thus pointing out the need to "consider fear of crime events at the smallest possible scale to be able to un-erroneously associate them spatially with 
elements of the environment" (Solymosi et al., 2015: 198). Certain community characteristics and neighbourhood-level social processes, such as the neighbourhood disorder, residential instability and racial composition are used to explain the worry about crime (Brunton-Smith and Jackson, 2012; Bruton-Smith and Sturgis, 2011).

On the other hand, the macro-level geographical distribution of the emotions about crime has been interpreted more as the distribution of general concerns and anxieties (or 'mental states' of worry) than as actual emotional responses towards crime (or 'mental events' of fear) (Hummelsheim et al., 2011; Vieno et al., 2013). Researchers analyse the international and regional distribution of worry about crime and feelings of unsafety and explain their geographical differences by making use of variables such as unemployment, crime rates, income inequality, rates of higher education and welfare state measures (Hummelsheim et al., 2011; Vauclair and Bratanova, 2017; Vieno et al., 2013; Visser et al., 2013). Note that the studies described below make use of different operational definitions of worry about crime and perceived unsafety. This literature review will serve as a basis to select potential area-level predictors (i.e. covariates in small area estimation) of worry about crime and produce reliable regional estimates.

Unemployment and income inequality are known to be two predictors of the macro-level geographical distribution of worry about crime and feelings of unsafety (Fitzgerald et al., 2012; Rueda and Stegmueller, 2015; Vauclair and Bratanova, 2017; Vieno et al., 2013). High unemployment and income inequality have been pointed out as 
macro-level signals for low social protection that increase concerns about economic and social insecurity, resulting into more feeling of unsafety and worry (Hummelsheim et al., 2011; Vieno et al., 2013; Visser et al., 2013). This is the reason why some argue that, when analysing the distribution of the emotions about crime at large geographical levels, these emotions might be interpreted as 'umbrella sentiments' people develop to disguise the high levels of social and economic insecurity in their societies (Vieno et al., 2013). Hummelsheim et al. (2011) measure the impact of country-level social protection on feelings of unsafety, concluding that political welfare measures, such as benefits in kind for families and expenditure on education, might reduce people's feelings of lack of protection and perceived unsafety.

Some researchers have shown that the actual crime rates are positively correlated to worry about crime (Fitzgerald et al., 2012; Krahn and Kennedy, 1985): "crime occurring in the broader region of the individual's immediate neighborhood had a significantly negative relationship with fear" (Breetzke and Pearson, 2014: 51). However, other studies show that crime rates affect only certain groups (e.g. white citizens (Liska et al., 1982)) or have no effect on feelings of unsafety (Hummelsheim et al., 2011; Vieno et al., 2013). The level of urbanisation and the population density are also related to worry about crime (Bruton-Smith and Sturgis, 2011).

Finally, certain individual factors such as age, gender, income or level of education have been well explored in academic research about emotions about crime 
(Gray et al., 2018; Hale, 1996; Killias, 1990; Pantazis, 2000). We expect ageing and less educated regions to have a higher proportion of citizens worried about crime.

\subsection{Mapping worry about crime: methodological limitations}

It has been shown that cross-national surveys, such as the ESS or the International Crime Victims Survey, are required to examine the macro-level explanations of worry about crime. However, survey data are limited for mapping phenomena at lower levels than the spatial scale designed by the original survey. ESS data, for example, are representative at a country level, but sample sizes are not representative for many spatial units within countries (e.g. Nomenclature of Territorial Units for Statistics 2 (NUTS-2) areas). Regions are, in most cases, unplanned domains.

To allow comparisons at smaller geographical levels than the scales planned by the survey, model-based small area estimation techniques introduce models to 'borrow strength' from related areas and produce reliable estimates of target parameters at small area level (Rao and Molina, 2015). In small area estimation, small areas are defined as areas/domains for which direct estimates of adequate precision cannot be produced (Rao and Molina, 2015: 2). Thus, methodologically, small areas are also large geographical units for which direct estimation techniques produce unreliable estimates. Available arealevel auxiliary data from the census and administrative data sources are required as covariates in area-level model-based estimation. 
The Relative Root Mean Squared Error (RRMSE) is the measure of reliability (accounting for precision and accuracy) used in small area estimation. We expect a reduction in the RRMSE when using model-based estimators compared to direct estimators. Moreover, model-based estimators that borrow correlated random area effects from neighbouring areas are expected to show smaller RRMSEs than traditional modelbased estimators, especially when the spatial autocorrelation of the variable of interest is high (Pratesi and Salvati, 2008), as is the case of our outcome measure (Wyant, 2008).

\subsection{Hypotheses}

Based on previous research, we expect to find higher dysfunctional worry about crime in Southern and Eastern-European regions than in Scandinavia and Central Europe:

H1. The proportion of citizens dysfunctionally worried about crime is higher in Southern and Eastern-European regions and lower in Scandinavian and Central-European regions.

In relation to the predictors (i.e. covariates in small area estimation) of the distribution of worry about crime, we expect the proportion of citizens worried about crime to be higher in:

H2. regions with higher unemployment rates,

H3. ageing regions,

H4. regions with lower education levels, 
H5. regions with higher crime rates, and

H6. regions with higher population density

Note that only covariates with available data for all regions have been included as hypotheses. Other possible covariates (e.g. inequality, deprivation, public investment on education/health) suffered from missing data in at least one region or were not available at the target geographical level. Thus, these could not be analysed.

From a methodological perspective, we expect that model-based small area estimators produce more reliable estimates than direct estimators. We also expect to find more precise estimates when producing model-based estimates with spatially correlated random area effects than traditional model-based approaches (i.e. the Empirical Best Linear Unbiased Predictor, EBLUP):

H7. Model-based small area estimation produces more reliable estimates than direct estimators.

H8. SEBLUP produces more reliable estimates than traditional EBLUP.

\section{Methodology}

\subsection{Data: European Social Survey}

Estimates will be produced from ESS 5 data (2010/11). The ESS is a biannual crossnational survey that has been conducted in 34 countries since 2001. We use the 2010/11 edition instead of a more current one due to the absence of newer data available: measures 
on worry about crime were not included in ESS questionnaires from the 6th edition onwards. ESS samples are designed to be representative of all population aged 15 and over in each participant country. In most countries, all geographical levels below country level are unplanned domains.

After deleting the samples from Israel, Russia, Switzerland and Ukraine, whose regions are not included in most comparative datasets at a European level, the ESS has a sample size of 46,391 citizens covering 24 countries: Austria $(n=2259)$, Belgium $(n=1704)$, Bulgaria $(n=2434)$, Croatia $(n=1649)$, Cyprus $(n=1083)$, Czech Republic $(n=2386)$, Denmark $(n=1576)$, Estonia $(n=1793)$, Finland $(n=1878)$, France $(n=1728)$, Germany ( $n=3031)$, Greece $(n=2715)$, Hungary $(n=1561)$, Ireland $(n=2576)$, Lithuania $(n=1677)$, Netherlands $(n=1829)$, Norway $(n=1548)$, Poland $(n=1751)$, Portugal $(n=2150)$, Slovakia $(n=1856)$, Slovenia $(n=1403)$, Spain $(n=1885)$, Sweden $(n=1497)$ and United Kingdom ( $\mathrm{n}=2422)$. Other European countries, such as Italy or Romania, were not included in ESS 5. ESS participant countries are responsible for producing their national sample designs (within common sampling principles); this is the reason why countries with different population sizes have similar sample sizes (see European Social Survey, 2010).

Geographical information at NUTS-2 level is available for all countries except United Kingdom and Germany, for which estimates will be produced at NUTS-1 level. In total, we will produce small area estimates for 192 regions across 24 countries. The 
average of citizens sampled per region is $\bar{n}=239.8$. Since most areas are large regions, the average sampling fraction is very low $(\bar{f}=0.0002)$. The areas with the smallest samples are the Spanish regions of Melilla $(n=5)$ and La Rioja $(n=9)$ and the German state of Saarland $(n=20)$. The areas with the highest samples are Estonia $(n=1793)$, Southern and Eastern Ireland $(\mathrm{n}=1717)$ and Lithuania $(\mathrm{n}=1677)$. Note that Estonia, Lithuania and Cyprus are countries with one single NUTS-2 region.

In order to allow international comparisons from ESS data, we have combined design and population weights to compute new weights (European Social Survey, 2014).

\subsection{Data: Outcome measure}

The ESS included (in its $3^{\text {rd }}, 4^{\text {th }}$ and $5^{\text {th }}$ editions) four questions to measure the worry about crime. Based on previous research, we combine these questions to analyse dysfunctional worry about crime: "if individuals who say they are fairly or very worried also report that their quality of life is reduced by either their worries or their precautions against crime, then assign these individuals to the dysfunctionally worried group" (Jackson and Gray, 2010: 5). Moreover, Jackson and Kuha (2014) computed the probabilities of ESS respondents to fall within six latent classes, in part, to distinguish between respondents functionally and dysfunctionally worried: those who reported no effect of worry on their quality of life had a higher probability to fall within the class of citizens unworried or functionally worried; while those who reported some effect had a 
higher probability to be within the class 'frequently worried' (and zero probability of falling within 'functionally worried'), and respondents whose worry had a serious effect on their quality of life tended to fall within the group of citizens 'persistently worried'. Both the classes 'frequent worry' and 'persistent worry' can be grouped within 'dysfunctional worry'.

We combine both questions to create simple categorical dichotomous measures of dysfunctional worry about burglary at home and dysfunctional worry about violent crime derived from the questionnaire (see Table 1). For each variable, individuals responding some worry ('All or most of the time', 'Some of the time' or 'Just occasionally') and some effect of worry on quality of life ('serious effects on the quality of life' or 'some effect') are coded as 1, while respondents with no worry or no effect of worry on quality of life are coded as 0 . 'Don't know', 'No answer' and 'Refusal' are coded as missing data. Note that this is also the operationalisation used by the ESS (European Social Survey, 2013).

\section{<Table 1 about here >}

In the case of worry about burglary at home, $26 \%$ of valid responses across all countries reported some worry and some effect of worry on quality of life; while the $25.5 \%$ reported some worry about violent crime and this worry affected their quality of life (see Table 2).

<Table 2 about here> 


\subsection{Data: Covariates}

Area-level covariates are required in area-level model-based small area estimation. Considering the substantive literature review, but also having in mind that covariates cannot have missing data for any area, we explored the correlation of different variables with our response variables to decide which covariates should be included in our models. Six covariates were finally included: (i) proportion of citizens unemployed aged 15 or more 2011, (ii) proportion of population aged 65 or more 2011, (iii) population density 2011, (iv) proportion of population aged 25-65 with tertiary education 2011, (v) intentional homicides per 100.000 inhabitants 2010, and (vi) burglaries of private residential premises per 1000 inhabitants 2010. All these measures are provided by EUROSTAT (http://ec.europa.eu/eurostat/data/database). Note that EUROSTAT does not publish regional crime statistics since 2010; this is the reason why two of our covariates refer to 2010. Model results are provided in section 4.1.

Other covariates were also explored, but their bivariate Spearman correlations (denoted as $\rho)$ with area-level dysfunctional worry about crime (measured here by direct estimates) were very small or not significant. Some examples are: Gross Domestic Product per capita (worry about burglary: $\rho=-0.28$, p-value $>0.05$ / worry about violent crime: $\rho=-0.37, p$ value $>0.05$ ), infant mortality (worry about burglary: $\rho=0.03$, p-value $>0.1 /$ worry about violent crime: $\rho=0.04, p$-value $>0.1$ ) and migration rate (worry about burglary: $\rho=-0.24$, p-value $>0.05$ / worry about violent crime: $\rho=-0.24$, $p$-value $>0.05$ ). 


\subsection{Method: SEBLUP based on Fay-Herriot model}

Small area estimates will be produced using three approaches: Horvitz-Thompson (HT) direct estimator, EBLUP under Fay-Herriot model, and SEBLUP with spatially correlated random area effects. See Appendix for details.

First, the HT direct estimator uses only area-specific sample data and survey weights to produce design-unbiased estimates (Horvitz and Thompson, 1952). Direct estimates can suffer from a high variance and unreliability in areas with small sample sizes.

Second, the EBLUP, which is based on Fay-Herriot model (Fay and Herriot, 1979), combines direct estimates with synthetic estimates in each area, with more weight attached to the direct estimate when the direct estimate's error is small, and more weight given to the synthetic estimate when the error of the direct estimate is large (Rao and Molina, 2015). Synthetic estimates are produced from fitting a model with a set of arealevel covariates. Thus, the EBLUP is preferred over regression-based synthetic estimates because it obtains an optimal combination between direct and synthetic estimates in each area; while regression-based estimates "are likely to be biased since they are not based on direct measurement of the variable of interest in the small area of interest" (Levy, 1979: 9).

Third, the SEBLUP adds spatially correlated random area effects to the EBLUP in order to borrow strength from neighbouring areas (Petrucci and Salvati, 2006; Pratesi 
and Salvati, 2008). It allows for more reliable estimates when the target variable shows medium/high levels of spatial autocorrelation, as is the case of our variable of interest (Wyant, 2008). A proximity matrix is needed to bring in spatially correlated random area effects. The proximity matrix used here follows a 'Queen contiguity' approach, which defines as neighbouring areas not only polygons that share borders, but also polygons that share vertices.

EBLUP and SEBLUP estimates' RRMSE are expected to be smaller than direct estimates' RRMSE (Pratesi and Salvati, 2008; Rao and Molina, 2015). RRMSEs of direct estimates are obtained from the Coefficient of Variation. EBLUP and SEBLUP's RRMSEs are computed from a parametric bootstrap ( $B=500$ replications) (Molina et al., 2009; Rao and Molina, 2015). Small area estimates and RRMSEs are produced using the 'sae' package for $R$ software (Molina and Marhuenda, 2015).

\section{Findings}

Findings are organised as follows. First, model results are presented. Second, SEBLUP estimates are mapped. Third, RRMSEs of all estimates are examined to check their reliability. Finally, model diagnostics of SEBLUP models are presented. 


\subsection{Fitting a model of worry about crime for small area estimation}

In order to produce reliable EBLUP and SEBLUP estimates, area-level models need to be fitted. Although the main objective of small area estimation models is to improve the estimates' reliability, model results provide a consistent set of information about the macro-level explanation of worry about crime, and hence we discuss these results below.

Table 3 shows the results of the EBLUP and SEBLUP models fitted to estimate dysfunctional worry about burglary at home, and Table 4 shows the results of the models fitted to estimate dysfunctional worry about violent crime. AIC and BIC measures are lower in the SEBLUP models than in the linear and EBLUP models, showing that modelbased small area estimation methods not only improve the estimates' reliability but also the models show a better goodness of fit. In the case of worry about burglary, the AIC measure is reduced from -242.3 of the linear regression to -329.1 of the SEBLUP; and, in the case of worry about violence, from -304.7 of the linear model to -347.6 of the SEBLUP. The BIC is reduced from -226.5 of the linear regression to -299.7 of the SEBLUP for worry about burglary; and from -250.6 of the linear model to -318.3 of the SEBLUP in the case of worry about violent crime.

<Table 3 about here $>$

<Table 4 about here> 
Both Table 3 and 4 show that, among all variables, the most explanatory covariate is the proportion of citizens unemployed: higher unemployment explains higher worry about burglary and violence (worry about burglary: $\beta^{E B L U P}=0.91, \beta^{S E B L U P}=0.62, p$ value $<0.001$ / worry about violent crime: $\beta^{E B L U P}=0.81, \beta^{S E B L U P}=0.68, p$-value $<0.001$ ) (H2). High unemployment is known to be a macro-level signal for low social protection that increase not only concerns and insecurities about the socio-economic problems of the region/country, but also specific worries towards crime and victimisation (Hummelsheim, 2011; Visser et al., 2013). Again, the macro-level worry about crime shows to be an 'umbrella sentiment', and it arises in regions where social and economic insecurity is high (Vieno et al., 2013).

The second strongest significant relation in both EBLUP models is shown between dysfunctional worry about crime and the proportion of citizens aged 65 or more (worry about burglary: $\beta^{E B L U P}=0.54, p$-value $<0.05 /$ worry about violent crime: $\beta^{E B L U P}=0.32, p$-value $\left.<0.05\right)(\mathrm{H} 3)$. However, the coefficients of the SEBLUP models show that the second strongest covariate is the proportion of citizens with higher education, which have negative model coefficients (H4) (worry about burglary: $\beta^{\text {SEBLUP }}=-0.39, \quad p$-value $<0.01 /$ worry about violent crime: $\beta^{\text {SEBLUP }}=-0.28, \quad p$ value $<0.01)$. Regarding the proportion of citizens with higher education, the difference between the EBLUP and SEBLUP model coefficients is small, while the coefficients referred to the proportion of citizens aged +65 are greatly reduced from EBLUP to 
SEBLUP models. Area-level models that do not account for spatially correlated random area effects might be overestimating the effect of the latter on the worry about crime. Thus, ignoring the spatial autocorrelation parameter when we aim to predict outcome measures with an implicit spatial dimension (Wyant, 2008) might lead to misleading results. Both variables (age and education level) are well-explored predictors in the study of fear of crime at individual and aggregated levels. These increase and reduce, respectively, the citizens' perceived vulnerability and, in turn, the worry about victimisation (Hale, 1996; Killias, 1990).

Police-detected rates of homicides and burglaries are also relevant to explain the regional distribution of worry about crime (H5) (Breetzke and Pearson, 2014; Krahn and Kennedy, 1985; Liska et al., 1982), though their effect sizes show smaller relations than the three prior covariates. The rates of both types of crimes correlate with the proportion of citizens worried about crime, but the homicide rate shows to be slightly more relevant that the rate of burglaries in both cases (worry about burglary: $\beta^{E B L U P}=0.03$, $\beta^{S E B L U P}=0.02, p$-value $<0.05 /$ worry about violent crime: $\beta^{E B L U P}=0.03, \beta^{S E B L U P}=0.03$, $p$-value $<0.01)$. Finally, the population density shows a significant but small relation with worry about crime. The estimated spatial correlation coefficient is $\hat{\rho}=0.70$ for worry about burglary and $\hat{\rho}=0.61$ for worry about violence. 


\subsection{Small area estimates of worry about crime at regional level in Europe}

Results from our model-based estimates reveal important differences in the worry about crime at a regional level in Europe. As will be shown in section 4.3, SEBLUP estimates have the lowest RRMSEs (i.e. are the most reliable estimates), and hence we focus on these.

In relation to the proportion of citizens dysfunctionally worried about burglary, SEBLUP estimates show a variation between the minimum of $\hat{\delta}^{S E B L U P}=2.1 \%$ in the Dutch province of Flevoland and the maximum of $\hat{\delta}^{S E B L U P}=62.6 \%$ in the Greek county of Atikki (where Athens is located). Particularly low dysfunctional worry about burglary at home is also estimated in the Spanish region of Extremadura $\left(\hat{\delta}^{S E B L U P}=2.7 \%\right)$ and the Norwegian regions of Vestlandet $\left(\hat{\delta}^{S E B L U P}=4.4 \%\right)$ and Trøndelag $\left(\hat{\delta}^{S E B L U P}=4.6 \%\right)$. At the other end, high dysfunctional worry about violent crime has been estimated in the Greek regions of Sterea Ellada $\left(\hat{\delta}^{S E B L U P}=62.5 \%\right)$, Ionia Nisia $\left(\hat{\delta}^{S E B L U P}=60.5 \%\right)$ and Peloponnisos $\left(\hat{\delta}^{S E B L U P}=52.8 \%\right)$. Nine of the ten most worried regions about burglary at home are from Greece.

With respect to the SEBLUP estimates of dysfunctional worry about violent crime, the least worried European regions are Flevoland (Netherlands) $\left(\hat{\delta}^{S E B L U P}=2.0 \%\right)$, Extremadura (Spain) $\left(\hat{\delta}^{S E B L U P}=2.9 \%\right)$, Jadranska Hrvatska (Croatia) $\left(\hat{\delta}^{S E B L U P}=3.3 \%\right)$ and Vestlandet (Norway) $\left(\hat{\delta}^{S E B L U P}=5.5 \%\right)$. The regions most worried about violent crime 
are the Greek regions of Ionia Nisia $\left(\hat{\delta}^{S E B L U P}=51.1 \%\right)$, Attiki $\left(\hat{\delta}^{S E B L U P}=49.5 \%\right)$, Sterea Ellada $\left(\hat{\delta}^{S E B L U P}=46.4 \%\right)$ and Peloponnisos $\left(\hat{\delta}^{S E B L U P}=45.2 \%\right)$. Again, eight of the ten most worried regions about violent crime are Greek, as discussed by Zarafonitou (2009). Descriptive statistics of the estimates are shown in Table 5.

\section{$<$ Table 5 about here $>$}

Although there is a very high correlation between the SEBLUP estimates of dysfunctional worry about burglary and worry about violent crime $(\rho=0.95$, pvalue $<0.001$ ), dysfunctional worry about burglary is higher than worry about violent crime in most regions. 125 of the 192 regions are more worried about burglary than about violent crime. Particularly interesting is that most regions with higher observed worry about violent crime than worry about burglary at home are concentrated in certain countries. For example, the seven Norwegian regions show higher worry about violence than worry about burglary. This trend is also shown in Poland, where 13 of its 16 regions report higher observed worry about violent crime than worry about burglary at home; Sweden, where this is shown in 7 of its 8 regions; and Lithuania. On the other hand, every single region within 11 countries (Croatia, Cyprus, Estonia, Finland, Greece, Hungary, Ireland, Netherlands, Portugal, Slovakia and Slovenia) show higher dysfunctional worry about burglary than worry about violence. The observed gap between worry about burglary at home and worry about violent crime is usually small: only 10 regions display 
differences greater than $3 \%$, and the seven of them belong to Greece, where dysfunctional worry about burglary is remarkably higher than worry about violent crime.

From a broader perspective, our estimates add evidence on research showing higher levels of worry about crime in Southern and Eastern/post-communist European countries and lower rates in Central and Northern Europe (H1) (Hummelsheim et al., 2011; Jackson and Kuha, 2014). Figures 1 and 2 illustrate the geographical distribution of SEBLUP estimates of dysfunctional worry about burglary at home and dysfunctional worry about violent crime, respectively. Darker shades of grey represent higher estimates of worry and lighter tones show a lower worry, according to groups defined by the quantiles of the combined estimates of the two outcome measures.

\section{<Figure 1 about here $>$}

<Figure 2 about here $>$

\subsection{Reliability checks}

In order to check the reliability of the estimates, Figures 3 and 4 show the estimated RRMSEs of the direct, EBLUP and SEBLUP estimates. RRMSEs are needed to check whether the reliability of the small area estimates is acceptable. As a rule, it is considered that small area estimates' RRMSEs should be lower than $25 \%$ to be accepted as reliable, estimates with RRMSEs higher than $25 \%$ should be used with caution and estimates with RRMSEs higher than 50\% are regarded as unreliable (Commonwealth Department of 
Social Services, 2015). SEBLUP estimates are expected to be the most reliable ones (Petrucci and Salvati, 2006; Pratesi and Salvati, 2008).

$<$ Figure 3 about here $>$

$<$ Figure 4 about here $>$

First, as expected, the SEBLUP estimates' average RRMSE is lower than the EBLUP and direct estimates' RRMSEs (H7/H8). In the case of dysfunctional worry about burglary, the average RRMSE is reduced from the $22.5 \%$ of direct estimates to $18.2 \%$ of EBLUPs and $17.2 \%$ of SEBLUPs. This reduction is also shown for worry about violent crime: from $22.6 \%$ of direct estimates, to $18.6 \%$ of EBLUPs and $16.9 \%$ of SEBLUPs. On average, the percentage relative difference (henceforth $\overline{R D \%}$ ) between the original direct estimates' RRMSE and the final SEBLUP estimates' RRMSE is $\overline{R D \%}=-10.07$ in the case of worry about burglary and $\overline{R D \%}=-10.09$ in the case of worry about violent crime; which show a large relative improvement of the estimates' measure of reliability. The maximum percentage relative difference between the RRMSEs of the direct and SEBLUP estimates is -67.24 in the case of worry about burglary and -68.34 in the case of worry about violent crime.

Second, it is important to focus on the area-specific RRMSE to assess the reliability of area-level estimates. While more than 60 areas have direct estimates' RRMSEs higher than $25 \%$ in both variables of interest, the number of small areas with SEBLUP estimates' RRMSEs higher than $25 \%$ is only 24 in the case of worry about 
burglary at home and 20 in the case of worry about violent crime. There is only one area whose SEBLUP estimates' RRMSEs are higher than $50 \%$, whose sample size is $n=25$.

\subsection{Model diagnostics}

Diagnostics of the SEBLUP models are presented below to examine whether our estimates are biased by the models and to check the models' validity (Brown et al., 2001). We present the q-q plots of the estimates' standardised residuals in Figures 5 and 6 to check the normality of the residuals. Standardised residuals of small area estimates have been produced based on Pratesi and Salvati (2008: 132). Figures 5 and 6 show that standardised residuals follow a normal distribution with slight variations at the tails. The Shapiro-Wilk statistic test for normality gives the value of $\mathrm{W}=0.99(\mathrm{p}$-value $=0.46)$ for worry about burglary and $\mathrm{W}=0.99$ (p-value=0.59) for worry about violent crime, which suggests fail to reject the null hypothesis of the normal distribution.

\section{<Figures 5 and 6 about here>}

Finally, figures 7 and 8 show the scatter plots of the direct estimates against the SEBLUP estimates. Regarding that direct estimates are design-unbiased, we expect a high linear correlation between direct and model-based estimates. As expected, regression model adjusted $R$-squared is very high $\left(R^{2}=0.96\right.$ for worry about burglary and $R^{2}=0.94$ for worry about violent crime). Both plots show that SEBLUP estimates are less extreme than direct estimates, shrinking extreme values towards the mean. 


\section{<Figures 7 and 8 about here $>$}

\section{Conclusions}

This research has produced estimates of dysfunctional worry about burglary at home and dysfunctional worry about violent crime for 192 regions across 24 European countries from ESS 5 (2010/11) data. We have produced direct, EBLUP and SEBLUP estimates. This paper illustrates that model-based small area estimation methods, and specifically the SEBLUP with spatially correlated random area effects, are potential tools to estimate and map variables of criminological interest at a small area level. SEBLUP estimates of dysfunctional worry about crime have shown to be more reliable than EBLUP and direct estimates. The models fitted in this research are limited by the availability of reliable auxiliary information (i.e. covariates): some variables explored in previous studies (e.g. income inequality, investment on health/education) could not be tested in this research.

Our estimates add evidence to research showing that Eastern and Southern European regions are the areas with highest proportions of citizens worried about crime (Jackson and Kuha, 2014). More specifically, our SEBLUP estimates show that Greek, Slovakian, Estonian, Lithuanian and Bulgarian regions have high proportions of citizens worried about crime, as well as certain regions in Portugal, Spain and South France. At the other end, most regions in Central Europe and Scandinavia show the lowest SEBLUP 
estimates of dysfunctional worry about crime, especially Dutch, Norwegian, Swedish, Danish and Finish regions, but also some exceptions in Poland, Croatia and Spain.

Our EBLUP and SEBLUP models suggest that unemployment is the best predictor (among the covariates included in our models) of dysfunctional worry about crime. Macro-level unemployment, as well as other variables such as inequality or low public investment on health and education, are known to be social signals of low public protection that increase concerns about the social and economic situation of one's region, and these affect the worry about crime (Hummelsheim, 2011; Visser et al., 2013). Note that variables such as inequality and public investment on health and education could not be tested in our models due to lack of available data. Vieno et al. (2013) argue that feelings of unsafety, at a macro-level, can be interpreted as 'umbrella sentiments' that hide unspecific concerns about the area's social and economic instability. Here we observe that regional estimates of worry about crime are most likely explained by joblessness (and thus socio-economic) insecurities, and therefore the conceptualisation of 'umbrella sentiment' might well apply also to the worry about crime at a regional level.

Ageing and less educated regions also show higher estimates of worry about crime in Europe. Both the age and the level of education are known to be good predictors for the citizens' perceived vulnerability, and thus explain the increased worry about crime, both at individual and aggregated levels (Hale, 1996; Pantazis, 2000). Further research is needed to examine the hidden theoretical mechanisms that explain why the strength of 
the effect of the proportion of older adults on the worry about crime is reduced in our spatial models.

The crime rates and the population density show significant but smaller correlations with worry about crime (Breetzke and Pearson, 2014; Fitzgerald et al., 2012). Some argue that the relation between the crime rates and macro-level worry about crime might be influenced by the media, which reflects and reproduces reported crime rates (Liska et al., 1982). On average, people show a higher dysfunctional worry about property crimes than personal crimes (Jackson and Kuha, 2014).

Further research might explore in greater depth the particularly high worry about crime in Greece. Zarafonitou (2009) argued that high fear of crime in Greece between 2004 and 2005, and in particular in Athens, could be related to high social and economic insecurities and perceived decline in quality of life. The growth on unemployment experienced in Greece after 2009 might be interpreted as a signal for low social protection that increased concerns about the social and economic situation, and in turn the worry about crime.

Model-based small area estimation has shown to be a potential tool to produce reliable small area estimates of survey-recorded criminological phenomena, especially when sample sizes are not large enough to allow reliable direct estimates. However, estimates need to be produced meticulously and model-based approaches with spatially correlated area random effects seem to be the most promising. Further applications of 
small area estimation techniques to the worry about crime might focus on producing small area estimates from Jackson and Kuha's (2014) composite measure of worry.

\section{Notes}

1. In 2008, the US Panel to Review the Programs of the Bureau of Justice Statistics suggested the use of model-based small area estimation to produce estimates of crime rates (Groves and Cork, 2008). Despite their potential, small area estimation techniques have rarely been applied in criminological research. Some examples are: Whitworth (2012) used a multilevel logistic regression approach to produce synthetic estimates of fear of crime at neighbourhood level in England; Taylor (2013) produced synthetic multilevel regression estimates of perceptions of antisocial behaviour at local authority level in England; and Brakel and Buelens (2014) used a Hierarchical Bayesian approach to estimate victimisation, perceived neighbourhood degeneration and contact with police at local level in Netherlands. 


\section{References}

Berenbaum H (2010) An initiation-termination two-phase model of worrying. Clinical Psychology Review 30: 962-975.

Brakel JA van den and Buelens B (2014) Covariate selection for small area estimation in repeated sample surveys. Statistics in Transition new series and Survey Methodology 16(4): 523-540.

Breetzke GD and Pearson AL (2014) The fear factor: Examining the spatial variability of recorded crime on the fear of crime. Applied Geography 46: 45-52.

Brown G, Chambers R, Heady P and Heasman D (2001) Evaluation of small area estimation methods - an application to unemployment estimates from the UK LFS. In: Statistics Canada (ed.) Symposium 2001 - Achieving data quality in a statistical agency: a methodological perspective. Ottawa: Statistics Canada.

Brunton-Smith I and Jackson J (2012) Urban fear and its roots in place. In: Ceccato V (ed) The urban fabric of crime and fear. New York: Springer, pp. 55-82.

Brunton-Smith I and Sturgis P (2011) Do neighborhoods generate fear of crime? An empirical test using the British Crime Survey. Criminology 49(2): 331-369.

Caro Cabrera M and Navarro Ardoy L (2017) Measuring fear of crime by the use of the CIS Barometers. Revista Española de Investigaciones Sociológicas 157: 23-44.

Castro-Toledo FJ, Perea-Garcia JO, Bautista-Ortuno R and Mitkidis P (2017). Influence of environmental variables on fear of crime: Comparing self-report data with physiological measures in an experimental design. Journal of Experimental Criminology 13(4): 537-545.

Ceccato V (2012). The urban fabric of crime and fear. In: Ceccato V (ed) The urban fabric of crime and fear. New York: Springer, pp. 3-33.

Commonwealth Department of Social Services (2015) Survey of disability, ageing and carers, 2012: Modelled estimates for small areas, projected 2015. Australia: ABS.

DuBow F, McCabe E and Kaplan G (1979) Reactions to crime. A critical review of the literature. Washington DC: US Department of Justice.

European Social Survey (2010) Sampling for the European Social Survey round V: Principles and requirements. Available at: https://www.europeansocialsurvey.org/docs/round5/methods/ESS5_sampling_g uidelines.pdf (accessed 9 December 2018).

European Social Survey (2013) Exploring public attitudes, informing public policy. Selected findings from the first five rounds. Available at: https://www.europeansocialsurvey.org/docs/findings/ESS1_5_select_findings.pd f (accessed 10 December 2018). 
European Social Survey (2014) Weighting European Social Survey data. Available at: https://www.europeansocialsurvey.org/docs/methodology/ESS_weighting_data 1.pdf (accessed 15 February 2019).

Fay R and Herriot R (1979) Estimates of income for small places: An application of James-Stein procedures to census data. Journal of the American Statistical Association 74: 269-277.

Ferraro KF (1995) Fear of crime. Interpreting victimization risk. Albany: State University of New York Press.

Fitzgerald J, Curtis KA, Corliss CL (2012) Anxious publics: Worries about crime and immigration. Comparative Political Studies 45(4): 477-506.

Gabriel U and Greve W (2003) The psychology of fear of crime. Conceptual and methodological perspectives. British Journal of Criminology 43: 600-614.

Gray E, Grasso M, Farrall S, Jennings W and Hay C (2018) Political socialization, worry about crime and antisocial behaviour: An analysis of age, period and cohort effects. British Journal of Criminology 59(2): 435-460.

Gray E, Jackson J and Farrall S (2011) Feelings and functions in the fear of crime. Applying a new approach to victimisation insecurity. British Journal of Criminology 51: 75-94.

Groves RM and Cork DL (eds) (2008) Surveying victims: Options for conducting the National Crime Victimization Survey. Washington: The National Academies Press.

Hale, C (1996) Fear of crime: A review of the literature. International Review of Victimology 4: 79-150.

Horvitz DG and Thompson DJ (1952) A generalization of sampling without replacement from a finite universe. Journal of the American Statistical Association 47(260): 663-685.

Hough M (2004) Worry about crime: mental events or mental states? International Journal of Social Research Methodology 7(2): 173-176.

Hummelsheim D, Hirtenlehner H, Jackson J and Oberwittler D (2011) Social insecurities and fear of crime: A cross-national study on the impact of welfare state policies on crime-relaxed anxieties. European Sociological Review 27(3): 327-345.

Jackson J and Gouseti I (2014) Fear of crime and the psychology of risk. In: Bruinsma G and Weisburd D (eds) Encyclopedia of criminology and criminal justice. New York: Springer, pp. 1594-1603.

Jackson J and Gray E (2010) Functional fear and public insecurities about crime. British Journal of Criminology 50: 1-22.

Jackson J and Kuha J (2014) Worry about crime in a cross-national context: A modelsupported method of measurement using the European Social Survey. Survey Research Methods 8(2): 109-125. 
Killias M (1990) Vulnerability: Towards a better understanding of a key variable in the genesis of fear of crime. Journal of Gerontological Nursing 5(2): 97-108.

Krahn H and Kennedy LW (1985) Producing personal safety: The effects of crime rates, police force size, and fear of crime. Criminology 23(4): 697-710.

Levy PS (1979) Small area estimation - synthetic and other procedures, 1968-1978. In: Steinberg J (ed) Synthetic estimates for small areas: Statistical workshop papers and discussion. Rockville, National Institute on Drug Abuse, pp. 4-19.

Molina I and Marhuenda Y (2015) sae: An R package for small area estimation. The $R$ Journal 7(1): 81-98.

Molina I, Salvati N and Pratesi M (2009) Bootstrap for estimating the MSE of the SEBLUP. Journal of Computational Statistics 24: 441-458.

Pantazis C (2000) 'Fear of crime', vulnerability and poverty. British Journal of Criminology 40(3): 414-436.

Petrucci A and Salvati N (2006) Small Area Estimation for spatial correlation in watershed erosion assessment. Journal of Agricultural, Biological, and Environmental Statistics 11(2): 169-182.

Pratesi M and Salvati N (2008) Small Area Estimation: The EBLUP estimator based on spatially correlated random area effects. Statistical Methods \& Applications 17: 113-141.

Rader NE (2004) The threat of victimization: A theoretical reconceptualization of fear of crime. Sociological Spectrum 24(6): 689-704.

Rao JNK and Molina I (2015) Small Area Estimation. Second edition. Hoboken: Wiley.

Rueda D and Stegmueller D (2015) The externalities of inequality: Fear of crime and preferences for redistribution in Western Europe. American Journal of Political Science 60(2): 472-489.

Solymosi R, Bowers K and Fujiyama T (2015) Mapping fear of crime as a contextdependent everyday experience that varies in space and time. Legal and Criminological Psychology 20(2): 193-211.

Taylor J (2013) Small Area Synthetic Estimation of perceptions of alcohol and drugrelated anti-social behaviour. $\mathrm{PhD}$ thesis, University of Portsmouth.

Vauclair CM and Bratanova B (2017) Income inequality and fear of crime across the European region. European Journal of Criminology 14(2): 221-241.

Vieno A, Roccato M and Russo S (2013) Is fear of crime mainly social and economic insecurity in disguise? A multilevel multinational analysis. Journal of Community \& Applied Social Psychology 23: 519-535.

Visser M, Scholte M and Scheepers P (2013) Fear of crime and feelings of unsafety in European countries: Macro and micro explanations in cross-national perspective. The Sociological Quarterly 54: 278-301. 
Whitworth A (2012) Sustaining evidence-based policing in an era of cuts: Estimating fear of crime at small area level in England. Crime Prevention \& Community Safety 14(1): 48-68.

Williams PW, McShane MD and Akers RL (2000) Worry about victimization: An alternative and reliable measure for fear of crime. The Western Criminology Review 2(2).

Wyant BR (2008) Multilevel impacts of perceived incivilities and perceptions of crime risk on fear of crime. Journal of Research in Crime and Delinquency 45(1): 3964.

Zarafonitou C (2009) Criminal victimisation in Greece and the fear of crime: A 'paradox' for interpretation. International Review of Victimology 16: 277-300. 


\section{Appendix. Direct and SEBLUP estimators}

\section{Direct estimator}

Let $\mathrm{d}=1, \ldots, \mathrm{D}$ denote the small areas for which we want to produce estimates of the target parameter. For a sample $\mathrm{s} \subset \Omega$ of size $\mathrm{n}$ drawn from the target population of size $\mathrm{N}$, the non-sampled units $\mathrm{N}-\mathrm{n}$ are denoted by $\mathrm{r}$. Hence, $\mathrm{s}_{\mathrm{d}}=\mathrm{s} \cap \Omega_{\mathrm{d}}$ is the sub-sample from the small area $d$ of size $n_{d}, n=\sum_{d=1}^{D} n_{d}$, and $s=U_{d} s_{d} \cdot r_{d}$ denotes the non-sampled units for the small area $\mathrm{d}$ of $\mathrm{N}_{\mathrm{d}}-\mathrm{n}_{\mathrm{d}}$ dimension.

The fundamental direct estimator available in the survey sampling literature is the Horvitz-Thompson (1952) estimator given by the following:

$$
\hat{\delta}_{\mathrm{d}}^{\mathrm{DIR}}=\mathrm{N}_{\mathrm{d}}^{-1} \sum_{i \in s_{d}} \mathrm{w}_{\mathrm{di}} \mathrm{y}_{\mathrm{di}}
$$

Where $\mathrm{w}_{\mathrm{di}}=\pi_{\mathrm{di}}^{-1}$ denotes the sampling weight, and $\pi_{\mathrm{di}}$ the inclusion probability of $i$ th unit from $d$ th area.

The variance of $\widehat{\delta}_{\mathrm{d}}$ is approximated by the following estimator (Rao and Molina, 2015):

$$
\operatorname{Var}\left(\widehat{\delta}_{\mathrm{d}}\right)=\frac{1}{\mathrm{~N}_{\mathrm{d}}^{2}} \sum_{\mathrm{i} \in \mathrm{s}_{\mathrm{d}}} \mathrm{w}_{\mathrm{di}}\left(\mathrm{w}_{\mathrm{di}}-1\right) \mathrm{y}_{\mathrm{di}}^{2}
$$




\section{SEBLUP based on Fay-Herriot model}

Let us consider a finite population portioned into D small areas, and we are interested in the small area means $\boldsymbol{\delta}_{\mathrm{d}}, \mathrm{d}=1, \ldots, \mathrm{D}$. We assume the following area level model:

$$
\mathbf{y}=\mathbf{X} \boldsymbol{\beta}+\mathbf{v}+\mathbf{e}
$$

where $\mathbf{y}=\left(\hat{\delta}_{1}^{\mathrm{DIR}}, \ldots, \hat{\delta}_{\mathrm{D}}^{\mathrm{DIR}}\right)^{\prime}$ is the vector of direct estimates for the D small areas, $\mathbf{X}=$ $\left(\mathbf{x}_{1}, \ldots, \mathbf{x}_{\mathrm{D}}\right)^{\prime}$ is a $\mathrm{D} \times \mathrm{p}$ matrix of explanatory variables for the $\mathrm{D}$ small areas, $\mathbf{v}=$ $\left(v_{1}, \ldots, v_{D}\right)^{\prime}$ is the vector of area effects, and $\mathbf{e}=\left(e_{1}, \ldots, e_{D}\right)^{\prime}$ is the vector of independent sampling errors, independent of $\mathrm{v}$ with $\mathbf{e} \sim \mathrm{N}\left(0_{\mathrm{D}}, \boldsymbol{\Psi}\right)$, where $\boldsymbol{\Psi}=\operatorname{diag}\left(\psi_{1}, \ldots, \psi_{\mathrm{D}}\right)$ is the known covariance matrix. $\boldsymbol{\delta}=\mathbf{X} \boldsymbol{\beta}+\mathbf{v}=\left(\delta_{1}, \ldots, \delta_{\mathrm{D}}\right)^{\prime}$ is a vector that collects the target small area parameters.

We assume that the vector of area effects follows a simultaneously autoregressive (SAR) process with unknown autoregression parameter $\rho \in(-1,1)$ and proximity matrix $\mathrm{W}$ :

$$
\mathbf{v}=\rho \mathbf{W v}+\mathbf{u}
$$

Model (3) and (4) is called Spatial Fay-Herriot (SFH) model. The matrix $\left(I_{D}-\rho W\right)$ is assumed to be non-singular where $\mathrm{I}_{\mathrm{D}}$ denotes the $\mathrm{D} \times \mathrm{D}$ identity matrix.

$$
\mathbf{v}=\left(\mathbf{I}_{\mathrm{D}}-\rho \mathbf{W}\right)^{-1} \mathbf{u}
$$

where $\mathbf{u}=\left(\mathrm{u}_{1}, \ldots, \mathrm{u}_{\mathrm{D}}\right)^{\prime}$ satisfies $\mathbf{u} \sim \mathrm{N}\left(\mathbf{0}_{\mathrm{D}}, \mathrm{A} \mathbf{I}_{\mathrm{d}}\right)$ for A unknown.

From (5) it implies that $\mathrm{v}$ has got mean 0 and covariance matrix $\mathbf{G}(\boldsymbol{\theta})=$ $\mathrm{A}\left[\left(\mathbf{I}_{\mathrm{D}}-\rho \mathbf{W}\right)^{\prime}\left(\mathbf{I}_{\mathrm{D}}-\rho \mathbf{W}\right)\right]^{-1}$, hence the covariance matrix of $\mathrm{y}$ is given by $\boldsymbol{\Sigma}(\boldsymbol{\theta})=$ $\mathbf{G}(\boldsymbol{\theta})+\boldsymbol{\Psi}, \boldsymbol{\theta}=(\mathrm{A}, \rho)^{\prime}$. The SFH model can be written as: 


$$
\mathbf{y}=\mathbf{X} \boldsymbol{\beta}+\left(\mathbf{I}_{\mathrm{D}}-\rho \mathbf{W}\right)^{-1} \mathbf{u}+\mathbf{e}
$$

The Best Linear Unbiased Predictor (BLUP) of $\delta_{\mathrm{d}}=\mathbf{x}_{\mathrm{d}}^{\prime} \boldsymbol{\beta}+\mathrm{v}_{\mathrm{d}}$ is called SBLUP (Petrucci and Salvati, 2006) and is given by:

$$
\tilde{\delta}_{\mathrm{d}}^{\mathrm{BLUP}}=\mathbf{x}_{\mathrm{d}}^{\prime} \widetilde{\boldsymbol{\beta}}(\boldsymbol{\theta}) \mathbf{b}_{\mathrm{d}}^{\prime} \mathbf{G}(\boldsymbol{\theta}) \boldsymbol{\Sigma}^{-1}(\boldsymbol{\theta})[\mathbf{y}-\mathbf{X} \widetilde{\boldsymbol{\beta}}(\boldsymbol{\theta})]
$$

$\widetilde{\boldsymbol{\beta}}(\boldsymbol{\theta})$ is the Weighted Least Squared (WSL) estimator of $\boldsymbol{\beta}$ and $\mathbf{b}_{\mathrm{d}}^{\prime}$ is a $1 \times \mathrm{D}$ vector $(0, \ldots, 0,1,0 \ldots, \ldots 0)$ with 1 in the d-th position. Replacing a consistent estimator of $\widehat{\boldsymbol{\theta}}$ for $\boldsymbol{\theta}$ in (7) we obtain the SEBLUP. 
Table 1. Classification of responses of worry about crime into two classes.

\begin{tabular}{|l|l|l|c|c|c|}
\hline \multicolumn{2}{|c|}{} & \multicolumn{3}{|l|}{ Worry about crime } \\
\cline { 4 - 6 } \multicolumn{2}{|c|}{} & Never & $\begin{array}{l}\text { Just } \\
\text { occasionally }\end{array}$ & $\begin{array}{l}\text { Some of the } \\
\text { time }\end{array}$ & $\begin{array}{l}\text { All or most } \\
\text { of the time }\end{array}$ \\
\hline \multirow{2}{*}{$\begin{array}{l}\text { Effect on } \\
\text { quality of } \\
\text { life }\end{array}$} & No effect & 0 & 0 & 0 & 0 \\
\cline { 2 - 5 } & Some effect & & 1 & 1 & 1 \\
\cline { 2 - 5 } & $\begin{array}{l}\text { Serious } \\
\text { effects }\end{array}$ & & 1 & 1 & 1 \\
\hline
\end{tabular}

Table 2. Frequencies of worry about burglary/violent crime and effect of worry on quality of life.

\begin{tabular}{|c|c|c|c|c|}
\hline & Never & $\begin{array}{l}\text { Just } \\
\text { occasionally }\end{array}$ & $\begin{array}{l}\text { Some of the } \\
\text { time }\end{array}$ & $\begin{array}{l}\text { All or most of } \\
\text { the time }\end{array}$ \\
\hline \multicolumn{5}{|c|}{ Worry about burglary at home } \\
\hline No effect & \multirow{3}{*}{$21198(39.8 \%)$} & $12774(24.0 \%)$ & $4765(9.0 \%)$ & $557(1.0 \%)$ \\
\hline Some effect & & $5726(10.7 \%)$ & $4799(9.0 \%)$ & $1226(2.3 \%)$ \\
\hline Serious effects & & $434(0.8 \%)$ & $757(1.4 \%)$ & $975(1.8 \%)$ \\
\hline \multicolumn{5}{|c|}{ Worry about violent crime } \\
\hline No effect & \multirow{3}{*}{$24333(46.0 \%)$} & $12550(23.7 \%)$ & $2425(4.6 \%)$ & $153(0.3 \%)$ \\
\hline Some effect & & $6337(12.0 \%)$ & $4523(8.5 \%)$ & $592(1.1 \%)$ \\
\hline Serious effects & & $475(0.9 \%)$ & $775(1.5 \%)$ & $777(1.5 \%)$ \\
\hline
\end{tabular}

Source: Own elaboration. Data from the ESS 5.

Table 3. EBLUP and SEBLUP models of dysfunctional worry about burglary.

\begin{tabular}{|c|c|c|c|c|c|c|c|c|}
\hline & \multicolumn{4}{|c|}{ EBLUP } & \multicolumn{4}{|c|}{ SEBLUP } \\
\hline & Coeff. & $\mathrm{SE}$ & $\mathrm{t}$-value & $\mathrm{p}$-value & Coeff. & SE & $\mathrm{t}$-value & $\mathrm{p}$-value \\
\hline (Intercept) & 0.102 & 0.07 & 1.9 & 0.073 & 0.172 & 0.07 & 2.6 & 0.010 \\
\hline $\begin{array}{l}\text { Proportion } \\
\text { unemployed }\end{array}$ & 0.910 & 0.17 & 5.4 & 0.000 & 0.624 & 0.19 & 3.1 & 0.001 \\
\hline $\begin{array}{l}\text { Proportion aged } \\
+65\end{array}$ & 0.539 & 0.25 & 2.2 & 0.034 & 0.299 & 0.25 & 1.1 & 0.041 \\
\hline Population density & 0.002 & 0.00 & 1.6 & 0.044 & 0.001 & 0.00 & 1.4 & 0.032 \\
\hline $\begin{array}{l}\text { Proportion tertiary } \\
\text { education }\end{array}$ & -0.426 & 0.11 & -3.8 & 0.001 & -0.389 & 0.17 & -3.4 & 0.001 \\
\hline Homicide rate & 0.028 & 0.01 & 2.6 & 0.010 & 0.023 & 0.01 & 2.3 & 0.015 \\
\hline Burglary rate & 0.009 & 0.00 & 2.1 & 0.037 & 0.007 & 0.00 & 1.5 & 0.021 \\
\hline AIC & \multicolumn{4}{|r|}{-278.86} & \multicolumn{4}{|r|}{-329.05} \\
\hline $\mathrm{BIC}$ & \multicolumn{4}{|r|}{-252.80} & \multicolumn{4}{|r|}{-299.73} \\
\hline Spatial correlation & & \multicolumn{4}{|r|}{0.70} \\
\hline
\end{tabular}


Table 4. EBLUP and SEBLUP models of dysfunctional worry about violent crime.

\begin{tabular}{|c|c|c|c|c|c|c|c|c|}
\hline & \multicolumn{4}{|c|}{ EBLUP } & \multicolumn{4}{|c|}{ SEBLUP } \\
\hline & Coeff. & SE & t-value & $\mathrm{p}$-value & Coeff. & SE & t-value & $\mathrm{p}$-value \\
\hline (Intercept) & 0.111 & 0.05 & 2.0 & 0.031 & 0.147 & 0.07 & 2.4 & 0.010 \\
\hline $\begin{array}{l}\text { Proportion } \\
\text { unemployed }\end{array}$ & 0.811 & 0.15 & 5.3 & 0.000 & 0.676 & 0.17 & 3.7 & 0.000 \\
\hline $\begin{array}{l}\text { Proportion aged } \\
+65\end{array}$ & 0.321 & 0.23 & 1.3 & 0.043 & 0.159 & 0.24 & 0.8 & 0.040 \\
\hline Population density & 0.002 & 0.00 & 1.5 & 0.037 & 0.001 & 0.00 & 1.3 & 0.044 \\
\hline $\begin{array}{l}\text { Proportion tertiary } \\
\text { education }\end{array}$ & -0.299 & 0.10 & -3.0 & 0.002 & -0.275 & 0.12 & -2.6 & 0.007 \\
\hline Homicide rate & 0.030 & 0.01 & 2.9 & 0.004 & 0.029 & 0.01 & 2.9 & 0.006 \\
\hline Burglary rate & 0.002 & 0.00 & 0.3 & 0.040 & 0.001 & 0.00 & 0.3 & 0.034 \\
\hline AIC & & & & -314.45 & & & & -347.59 \\
\hline $\mathrm{BIC}$ & & & & -288.39 & & & & -318.27 \\
\hline Spatial correlation & & & & & & & & 0.61 \\
\hline
\end{tabular}

Table 5. Summary of small area estimates of dysfunctional worry about crime and average RRMSE.

\begin{tabular}{|l|r|r|l|r|r|r|r|}
\hline & Minimum & $\begin{array}{l}\text { Lower } \\
\text { quartile }\end{array}$ & Mean & Median & $\begin{array}{l}\text { Upper } \\
\text { quartile }\end{array}$ & Maximum & $\begin{array}{r}\text { Average } \\
\text { RRMSE }\end{array}$ \\
\hline Worry about burglary at home \\
\hline Direct & $1.6 \%$ & $13.4 \%$ & $23.3 \%$ & $19.5 \%$ & $31.1 \%$ & $72.0 \%$ & $22.5 \%$ \\
\hline EBLUP & $2.0 \%$ & $14.3 \%$ & $22.6 \%$ & $19.7 \%$ & $28.9 \%$ & $59.4 \%$ & $18.2 \%$ \\
\hline SEBLUP & $2.4 \%$ & $14.4 \%$ & $22.5 \%$ & $19.8 \%$ & $28.9 \%$ & $63.0 \%$ & $17.2 \%$ \\
\hline Worry about violent crime \\
\hline Direct
\end{tabular}


Figure 1. SEBLUP estimates of dysfunctional worry about burglary.

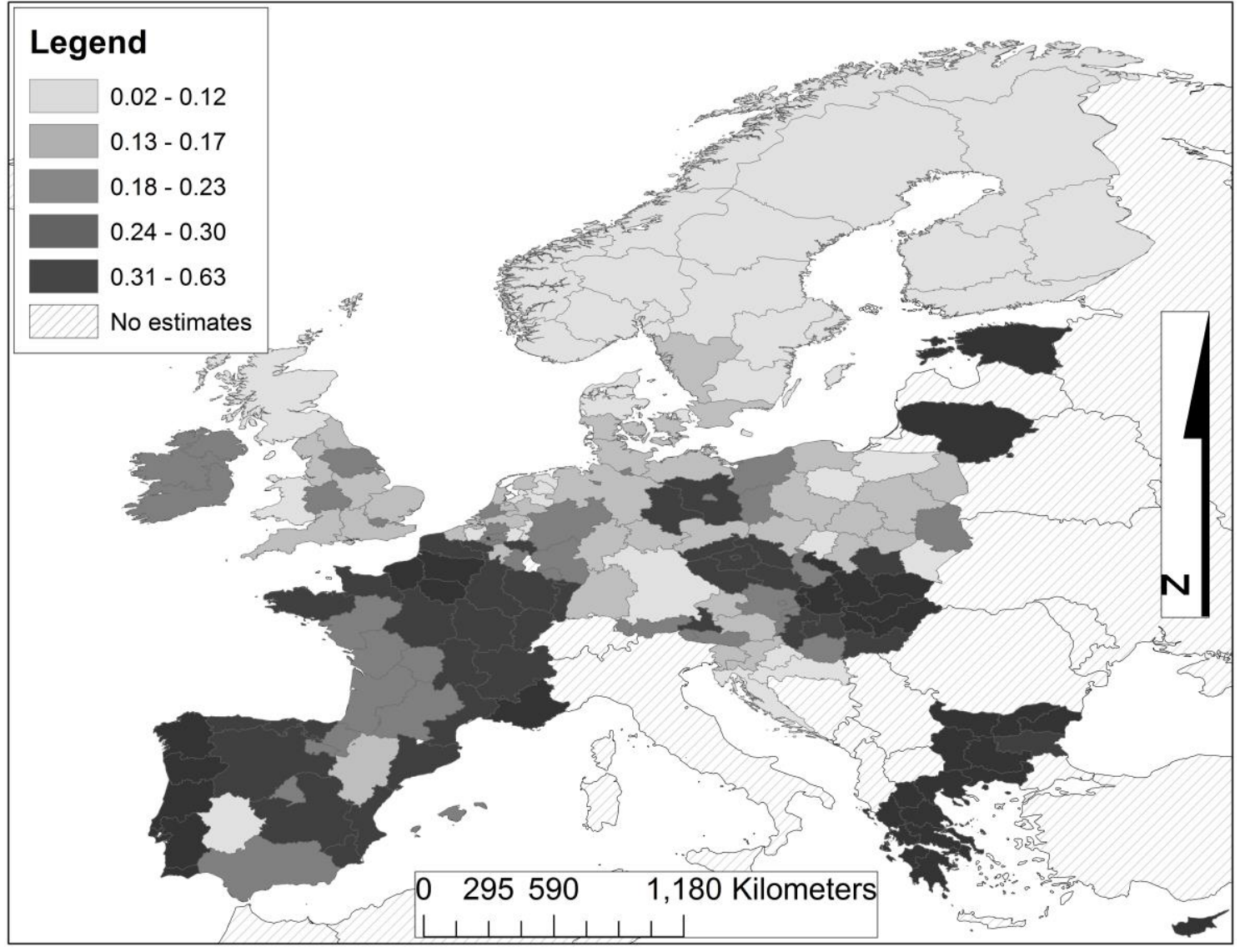


Figure 2. SEBLUP estimates of dysfunctional worry about violent crime.

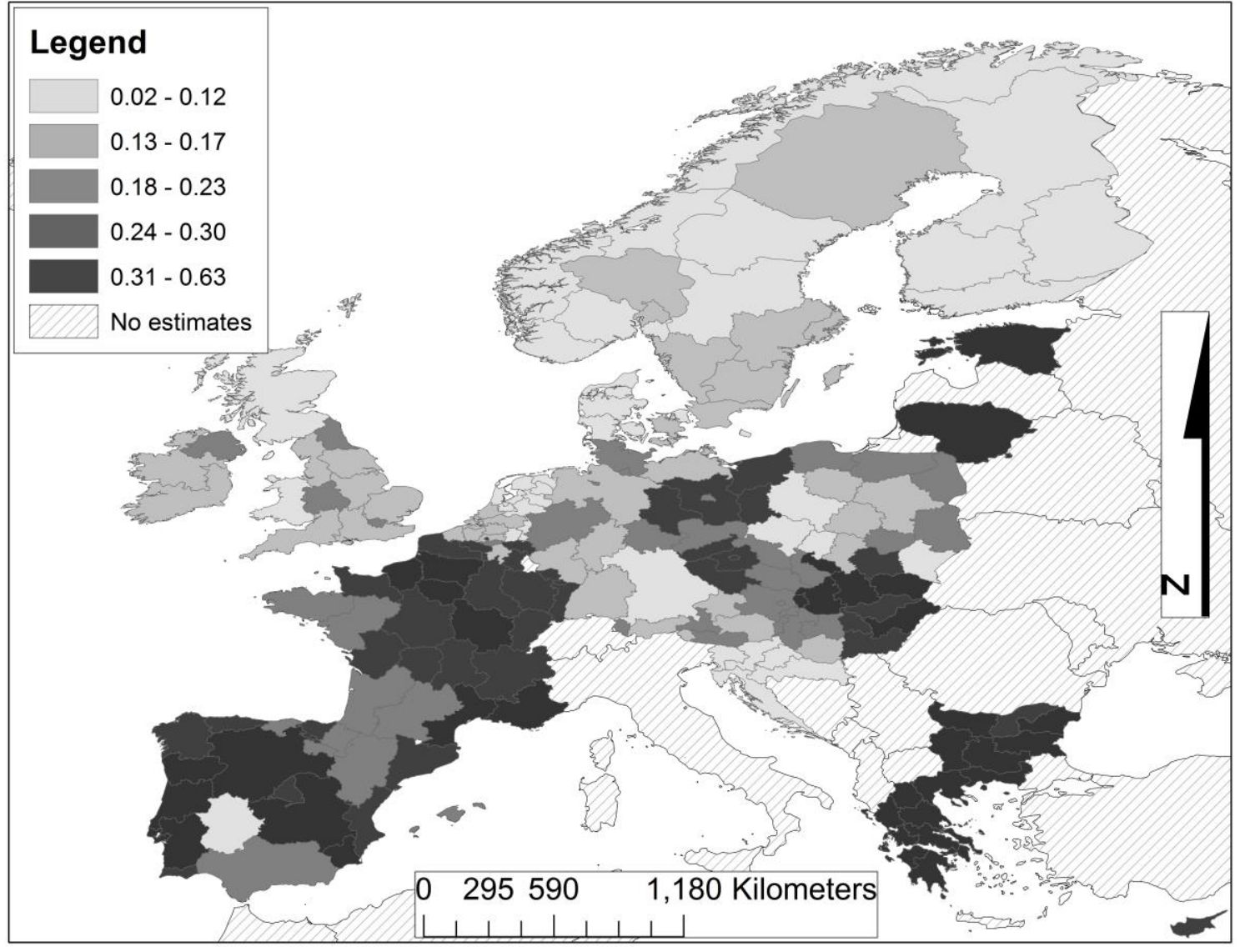


Figure 3. RRMSEs of direct, EBLUP and SEBLUP estimates of worry about burglary (ordered by sample sizes).

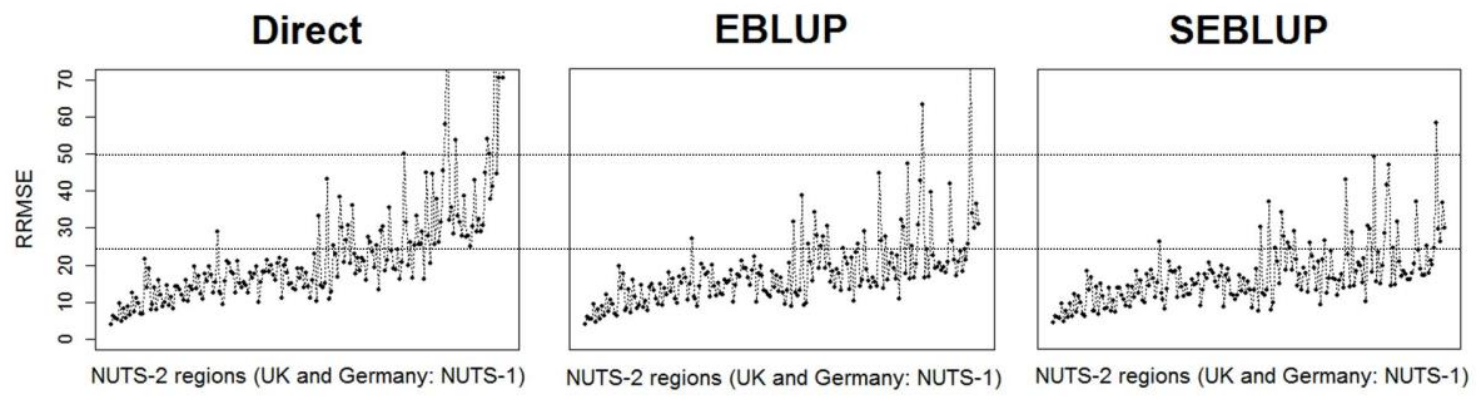

Figure 4. RRMSEs of direct, EBLUP and SEBLUP estimates of worry about violent crime (ordered by sample sizes).

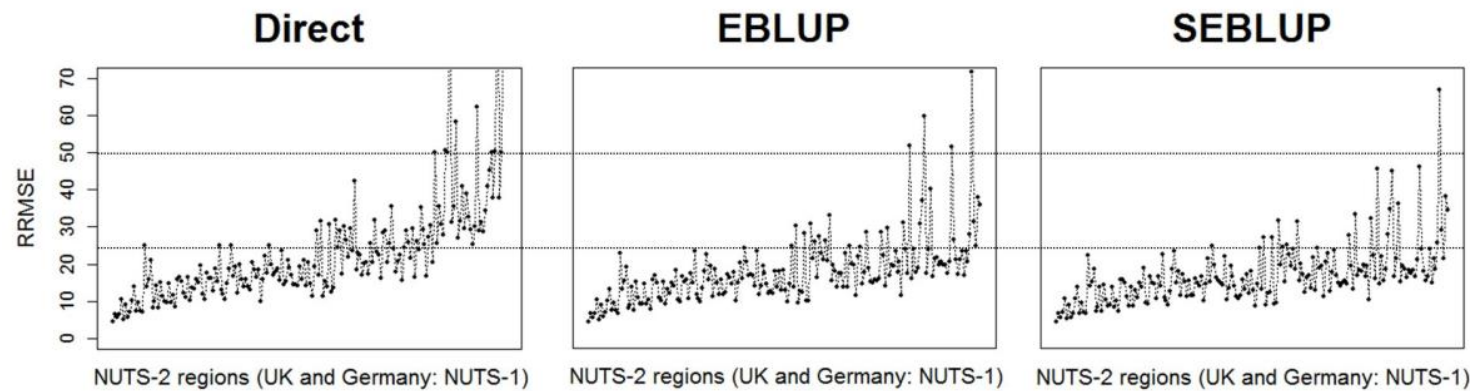


Figures 5 and 6. Normal q-q plots of standardised residuals of SEBLUP estimates.

Q-Q Plot. Worry about burglary at home Q-Q Plot. Worry about violent crime

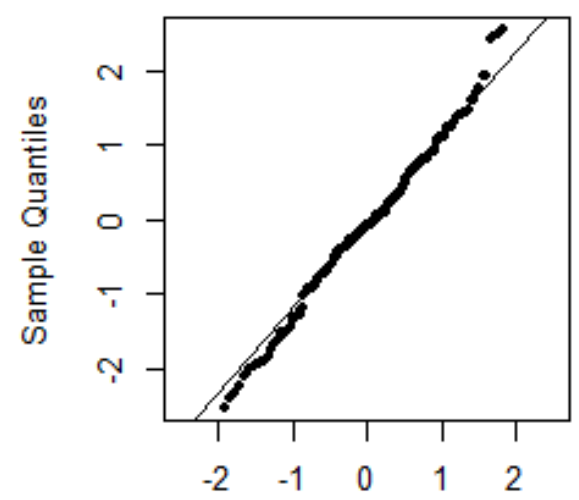

Theoretical Quantiles

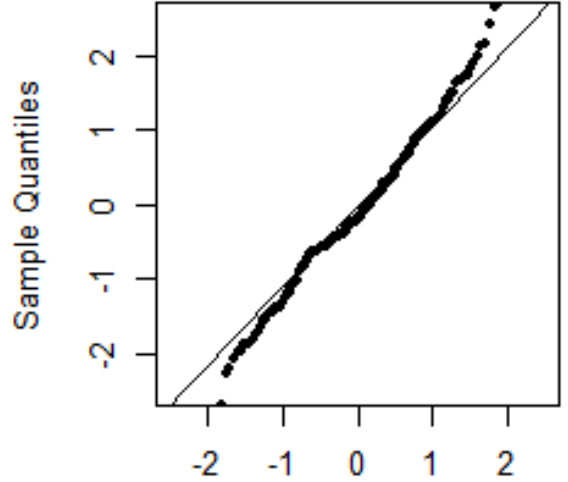

Theoretical Quantiles

Figures 7 and 8. Direct estimates versus SEBLUP estimates, $x=y$ line (solid) and linear regression fit line (dash).

Worry about burglary at home

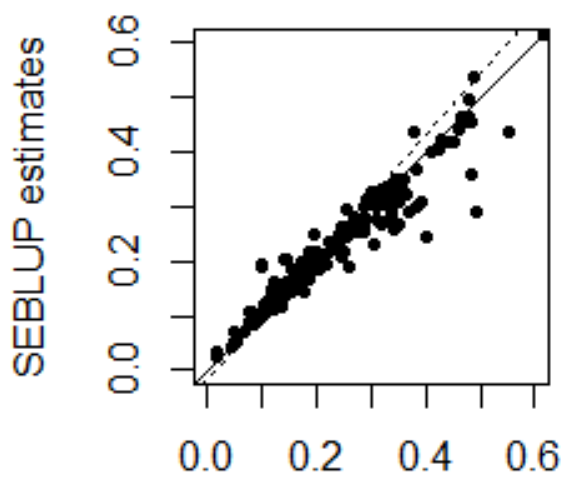

Direct estimates
Worry about violent crime

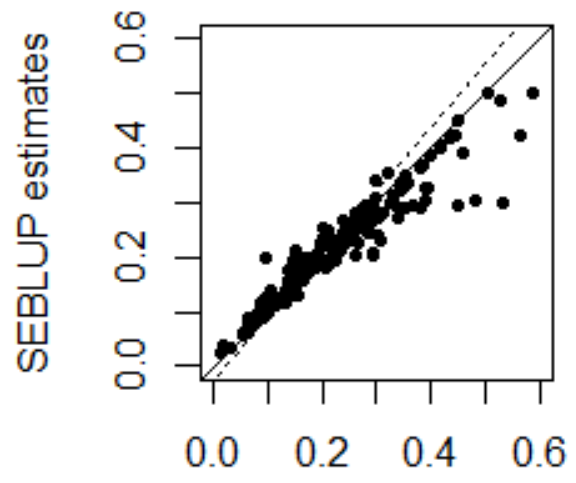

Direct estimates 